\title{
LOS RESTOS ARQUITECTÓNICOS DE LA PUERTA DE MEDINA LAQUANT
}

\author{
Por \\ MARIUS BEVIA
}

1

Para el conocimiento de las morfologías urbanas islámicas del País Valencià, están en la actualidad desarrollándose dos vías de estudio científico complementarias. La primera de ellas es la que hace referencia al estudio de las "Ciudades Muertas", o sea aquellas ciudades que fueron abandonadas antes o en los años de la conquista cristiana, constituyéndose en la actualidad grandes campos arqueológicos, como son el caso de Asp o el Viejo o la Rábita de Guardamar (1).

Su estudio nos está aportando y aportará en el futuro, valiosísimos datos sobre la vida urbana musulmana en nuestras tierras, con la gran ventaja de que sus estructuras no han sido transformadas con las posteriores ocupaciones de otras culturas.

La otra vía de investigación, es la que hace referencia a las «Ciudades Vivas", o sea aquéllas que tras la conquista fueron reutilizadas por los cristianos y que afecta a la mayoría de las grandes poblaciones del País, continuando latente en ellas las líneas morfológicas básicas originarias.

A diferencia'de las "Ciudades Muertas", su conocimiento estrictamente arqueológico presenta una mayor dificultad, al estár el primitivo solar urbano ocupado por edificaciones posteriores. No obstante y mediante todo un conjunto de manifestaciones materiales, como son los restos arquitectónicos y parcelarios, la planimetría histórica, costumbres y tradiciones, textos medievales, etc... podemos conocer su ordenación urbana de época musulmana.

No es absurdo decir que en toda "Ciudad Viva" sus características urbanas fundamentales han pervivido, incluso han condicionado su desarrollo de épocas más inme-

(1) Poblaciones en fase de excavación y estudio por parte de su director Rafael Azuar. Se han publicado las siguientes avances: AZUAR, R. "Excavaciones en el poblado fortificado árabe denominado Castillo del Rio (Aspe, Alicamte)." Saitabi XXXIll. Valencia 1983 1985 .

AZUAR, R. "Una Pompella de epoca islámica en Guardamar." Papers d`Educació i Culturà. N. ${ }^{\circ}$ 4, pag. 29. Valencia 
diatas. De tal manera que si bien las ciudades musulmanas cristianizadas han ido reorganizándose en base a la nueva ideología urbanística, lo han hecho partiendo de los elementos de la cultura anterior, y por lo tanto, aunque transformados y fosilizados, han permanecido hasta los tiempos actuales los elementos representativos del urbanismo musulmán.

Es por lo anterior que realizando una cuidadosa lectura urbana, con los elementos materiales perviventes y utilizando modelos urbanos extraídos de ciudades musulmanas no transformadas (2), podemos llegar a un conocimiento satisfactorio de las "Ciudades Vivas", e incluso en algunos casos sorprendente.

No obstante esta vía de estudio tiene una importante limitación, su conocimiento se hace con respecto a la ciudad cristiana, que cronológicamente lo que nos aporta son las estructuras urbanas de útima época, es decir las estructuras musulmanas del siglo XII hasta mediados del XIII.

Este es el caso de la Ciudad de Alacant, que hemos ido estudiando en otros trabajos puntuales (3). Con este método hemos ido conociendo la morfología islámica de Medina Laquant, y con la fortuna de ir descubriendo restos arquitectónicos que se suponian desaparecidos.

Así se pudo en el año 85 localizar y posteriormente excavar la Torre de la Pólvora, elemento defensivo situado en la muralla islámica, en estudio actualmente por su director de excavaciones R. Azuar.

Igualmente hemos localizado restos de gran interés de la Porta Ferrissa. objeto de este artículo, y que se suponía totalmente derribada en 1860.

Este elemento defensivo urbano se encontraba en el extremo del eje principal de la medina islámica, la calle Vila Vella, v en él confluian los dos brazos de murallas que bajando de la alcazaba cerraban el núcleo de población.

Estaba situada en un punto de evidente valor estratégico, a 10 metros sobre el nivel del mar y se accedía a ella mediante una empinada cuesta, todavía hoy visible en el tramo final de la calle Mayor. De tal manera que su valor militar, junto con las murallas que de ella partían, se mantuvo hasta finales del XVIII como posible último reducto defensivo de la ciudad, si eran tomadas sus otras defensas. De ello hay abundantes documentos históricos, tales como el que nos da en el siglo XIV el Cronista Muntaner, diciéndonos que no era posible tomar la Villa Vella si no se tomaba previamente el Castillo; o el del Cronista Bendicho que recomienda a mediados del XVII que se repare la línea defensiva de la ciudad Islámica para que sirva de último refugio la Vila Vella; o el que nos proporciona el ingeniero Pavón en el proyecto de acondicionar estas defensas todavía en 1751 (4).

(2) EPALZA, M. de; "Un modelo operativo de urbanismo musulman." Shara Al-Andalus, n. ${ }^{\circ} 2$. Alicante 1985

(3) AZUAR, R.; "Castellología Medieval Alicantina. Área Meridional." Castillo de Alicante. (Hisn Laqant.) Alicante 1981. AZUAR, R.; "Cataleg de Monumnets I Conjunts de la Comunitat Valenciana." I. Castillo y fortaleza de Santa Bárbara. Valencia 1983.

BEVIA M : "Formació del País Valencià i canvi urbà: el cás d'Alacant." L'Espill 15. Valencia 1982 BEVIA. M.: "L Albacar musulma del Castell d'Alacant." Sarq Af.Andalus n ${ }^{\circ} 1$. Alicante 1984.

BEVIA. M.; "Bovalars, carns i rafals: la casa del Rafali đAlacant." Sarq Ai-Andalus. n. 2 . Alicante 1985

BEVIÄ. M.: "Alacant: banyc, aigua i ciutat musulmana." Baños árabes en el País Valenciano. Valencia 1986

EPALZA, M de: "Alacant árab i els seus mercats. "Revista de Fogueres de Sant Joan." Alicante 1985

EPALZA, M. de; "Estudio del texto de Al-lorisi sobre Alicante. Sarq Al-Andalus $n{ }^{\circ} 2$. Alicante 1985.

EPALZA, M. de; "Costas alicantinas y costas magrebies: el espacio marítimo musulmán según los textos árabes "

(4) MUNTANER, R: "Crónica." Vol. V. Barcelona 1927.

"... Que avallaren a ell a la vila d'avali, com veeren que el Castell era perdut, e coneixien que no es podien pus teni en la vila, dintre, vella i que per cert, si el castell no fos estat pres, ells nulls temps no foren retuts al senyor rei. 
Esta característica es de mucho interés ya que se contrapone con la hipótesis emitida en algunos trabajos recientes sobre el uso que se hizo de esta parte de la ciudad, la Vila Vella, por parte de los conquistadores cristianos. Según estos trabajos la población mudéjar quedó ocupando esta área urbana, mientras los cristianos desarrollaron el raval de Sant Nicolau (5). Esta hipótesis, además de otro tipo de argumentaciones, sobre las cuales no vamos a entrar aquí puesto que exceden el ámbito de este artículo, desde el punto de vista militar es insostenible. No tiene sentido que tras haber conquistado por las armas la villa musulmana en 1246-47 se les deje en el lugar de mayor defensa, como hemos visto anteriormente, ocupando tan sólo los cristianos las partes bajas y peor defendibles.

III

Son dos los únicos documentos escritos que nos hablan de la Puerta Ferrissa conocidos hasta hoy.

El primero de ellos nos lo proporciona el Cronista Bendicho y ha sido objeto de lecturas incorrectas por parte de otros investigadores. Hablándonos de Santa Maria nos dice:

"Dedicole pues este templo de quien hablamos el Rey D. Alfonso a la Virgen Santísima, en esta parte de la ciudad más antigua a quien comúnmente llamamos la Villa Vieja, en la falda o vertiente del Castillo sobre el muro de esta población donde estaba la mezquita de los moros de aquella partida ciudad y aún hay vestigios de la puerta que entonces tenía, que es enfrente del brocal que está en medio de la callen (6).

Es decir, que aún vio los vestigios de la puerta que entonces tenía aquella partida ciudad, la Vila Vella y la Vila Nova divididas por el recinto islámico, y no se está refiriendo a la puerta de la mezquita, sino a la de la ciudad, como han pretendido otros autores.

Un argumento que refuerza esta lectura nos lo da el estudio de las fábricas del Templo de Santa María. No puede observarse ningún resto que pueda ser identificado como de época musulmana, e incluso considerando el estado de los muros anteriormente a las reformas del siglo XVII y XVIII.

Otro aspecto a tener en cuenta es el de que Bendicho en su Crónica, de difícil comprensión en algunos momentos, y por tanto equívoca, hace una descripción muy exaustiva de la ciudad en su momento. $Y$ por tanto no le pasa desapercibido ningún elemento arquitectónico de interés histórico de cierta significancia. Así vemos como nos habla de baños musulmanes, mezquitas, lonja gótica, ruinas del Tossal de Manises, Els Antigons, El Campello, acueductos romanos, etc,... Y por tanto la puerta Ferrissa no le pasó desapercibida, teniendo en cuenta además que aún conservaba caracteres que la definían como un elemento de época islámica.

La otra descripción, mucho más completa, que tenemos es la que nos proporciona en 1863 N. C. Jover acompañándola de un interesante grabado:

BENDICHO, V. : «Crónica de la Muy Ilustre. Noble y Leăl Ciudad de Alicante." Libro 1. Capítulo XIII. Alicante 1640 "Tiene a la mitad de la sierra un antiguo muro de tapias fortísimo fabricado que se dice la fortaleza antigua que defen. dia la Vila vieja que es en lo más allo de la ciudad. Y quien lo demás de ella en casa de urgente $y$ de necesidad tiene una segunda retirada....

151 DEL ESTAL, J. M., "Conquista y repoblación de Orihuela y Alicante por Alfonso X El Sabion. R.1.E.A., n. ${ }^{\circ} 33$. Alicante, 1987 HINOJOSA MONTALVO, J; "Historia de la Provincia de Alicante. Edad Media. Iil. Las estructuras sociales. El Alicante Medieval." Pag. 429. Alicante 1985

RAMOS HIDALGO, A.; "Evolución urbana de Alicante". Pag 70. Alicante 1984

(6) BENDICHO, V: Idem. Libro I. Capitulo XXIV 
"... la puerta Ferrissa, edifico que aun ecsistia a fines del año 1960, y que era el único monumento que se conservaba del tiempo de los moros, aunque de su construcción primitiva quedava muy poca cosa.

Hoy sería difícil fijar á que género de arquitectura pertenecia su conjunto: el arco que miraba á la calle mayor era un medio punto esencialmente árabe, como lo probaba, á mas de su forma y del corte y colocación de los sillares, una inscripción del Koran, cuyos caracteres, casi borrados por el tiempo, se distinguian hace pocos años en torno de su clave: la fachada que miraba á la Villa-vieja se elevaba sobre un arco ojivo, y así como la portada lateral que servía de ingreso al patio que había delante del edificio, era de fecha muy posterior, pues se construyó en 1541 cuando fue adjudicado aquel palacio al duque de Maqueda marqués de Elche, por los servicios que prestó al emperador Cárlos $V$ contra las comunidades de Castillan. (7)

Esta descripción aparte de darnos indudables datos sobre el carácter islámico del edificio, también nos habla de una importante transformación en posteriores épocas.

Además de estas dos noticias y del conocido grabado de C. N. Jover, tenemos el interesantísimo proyecto de Estevan de Pavón, realizado, como hemos dicho antes, pàra reforzar la Vila Vella como última retirada de la ciudad aprovechando los restos de la muralla árabe (8).

En él podemos ver la planta, los alzados posterior y anterior, así como una sección longitudinal de la puerta. Todo ello realizado con la suficiente precisión que nos permite realizar algunas interpretaciones sobre su cronología.

Según estos planos, la puerta Ferrissa era de entrada recta, abierta sobre un gran orreón. Con dos arcos de entrada, el primero de mayor altura y anchura, y el segundo de menores dimensiones. La diferencia de alturas permitía la existencia de una apertura en la primera parte de la bóveda para mejor defensa de la puerta de hierro que cerraba el segundo arco.

Continuaba el ingreso cubierto con dos bóvedas de medio cañón en sentido transversal a la de la puerta de ingreso, para abrirse a la calle Vila Vella con arco apuntado de mayores dimensiones que tódos los demás.

Lateralmente a este paso cubierto se abrian la puerta y ventanas del edificio colateral, que junto con la puerta formaban el Palacio del Duque de Maqueda. Igualmente sobre las bóvedas de la puerta existían un par de habitaciones con huecos a las dos calles, Mayor y Vila Vella.

En el lado derecho de la puerta existían un conjunto de patios amurallados, con aspilleras, siendo uno de sus muros la antigua muralla que bordeando Santa María llegaba hasta el Portal Nou, cerrando la Vila Vella por el lado del mar.

En uno de ellos estaba construida la gran escalera por la cual se subía a la parte delantera de la puerta.

La fachada principal estaba resuelta, como se puede ver con facilidad, con sillería de corte muy regular. Se remataba el edificio con una corsera a lo largo de todo su coronamiento y sobre ella se abrían un conjunto de aspilleras circulares rematadas en cruz.

\footnotetext{
(7) JOVER, N.C.; "Reseña histórica de Alicante." Alicante 1863.

(8) SERVICIO HISTORICO MILITAR-ESPAÑA. Plano 2584, sig. 3-2-12, hoja 5
} 
La fachada recayente a la calle Vila Vella, según el diferente tratamiento gráfico, debia estar construída con mampostería, estando rematada con un conjunto de aspilleras.

De las descripciones realizadas anteriormente se despreinde una clara conclusión: estamos ante un edificio en lo fundamental de finales del siglo XV o primera mitad del $X V \mid$, correspondiente a la última época de la arquitectura militar medieval. Si además comparamos algunos de sus elementos constructivos, como la corsera y las aspilleras circulares, con otros existentes en el Palacio de Altamira de Elx (9), veremos su absoluta identidad. Hecho que no debe sorprendernos ya que son del mismo propietario y época: los Marqueses de Elx y principios del XVI.

No obstante y gracias a la descripción de N. C. Jover sabemos que existía un "arco de miedio punto esencialmente árabe como lo probaba a más de su forma y del corte y colocación de los sillares, una inscripción del Koran....) O sea que había un arco de herradura con una leyenda coránica o al menos en árabe en su clave, realizado con despiece y técnica de sillares diferente al resto de la fábrica, lo suficientemente claro para que nuestro cronista del siglo pasado los pudiera distinguir.

Nos encontramos por lo tanto frente a una puerta musulmana reestructurada en la primera mitad del siglo XVI, hecho muy frecuente dada la necesidad de ir adecuando los elementos defensivos en cada momento. De la lectura del plano de Pavón y siguiendo otros modelos, nos atrevemos a avanzar una hipótesis sobre su primitiva morfología, esperando que unas futuras excavaciones la puedan verificar.

Siguiendo las líneas de las murallas nos encontramos que éstas cortan al edificio, formando dos torres rectangulares en la parte delantera. Igualmente en la sección transversal se puede observar que el segundo cuerpo de bóvedas se encuentra a mayor altura que la bóveda que cierra el primer arco. Por lo que suponemos que todo este cuerpo se añadió posteriormente. Igualmente la fachada delantera fue recubierta con sillares y rematada con la corsera, con lo que nos encontraríamos con una puerta de entrada recta franqueada por dos torreones, abierta con un arco de herradura y de una altura sensiblemente inferior, guardando un gran paralelismo con otras del recinto califal de Córdoba, como la puerta de Almodóvar (10). Esta hipótesis se ha grafiado en el plano $n .^{\circ} 4$

\section{IV}

La comparación de la planta de la Porta Ferrissa y su área de influencia con el parcelario catrastal actual nos ha permitido comprobar que este edificio no fue, afortunadamente, derribado en su totalidad en 1860. Si observamos ambos planos veremos que las parcelas existentes son las mismas, que las actuales edificaciones no las han variado, y que además han utilizado en su mayor parte como muros medieros las de las antiguas edificaciones.

Los edificios existentes en área son todos ellos de la segunda mitad del XIX, época en la que no se procedía al derribo integral de las edificaciones preexistentes, sino que se aprovechaban aquellas partes de valor constructivo;

Este hecho nos llevó a un estudio de las edificaciones, pudiendo comprobar la existencia de restos de la cerca musulmana y de la Porta Ferrisa.

\footnotetext{
19) AZUAR, R.; "Catàleg de Monuments i Conjunts de la Comunitat Valenciana." I. Palacio Altamira. Valencia 1983

(10) TORRES BALBAS, L.; "Puertas de recintos musulmanes en España." Castillos de España. Segunda Época. $12 . \mathrm{n} .{ }^{\circ} 79$. Madrid 1973
} 
En el número 42 de la calle Mayor se conserva una esquina de la Porta Ferrissa reutilizada en parte como entrada y lateral de la caja de escaleras, hasta una altura de tres plantas, como aparece grafiada en el plano $n .^{\circ} 6$. Aunque hoy se encuentra enlucida con yeso, en unas catas de urgencia que se realizaron, se pudo comprobar la existencia de un muro de sillares bien labrados y de tamaños semejantes, que a primera vista recuerdan los aparecidos en la Torre de la Pólvora. En una primera apreciación el resto superviviente corresponde a la parte de la puerta reestructurada en época cristiana.

Esperamos que prontamente se pueda realizar un estudio arqueológico sobre este resto arquitectónico, y que damos como novedad en este artículo

Como se puede ver en el plano parcelario y en el grabado de N. C. Jover esta esquina se salvó de la piqueta debido a que al tirar la nueva línea de la caile Mayor quedaba dentro del área de las casas, derribándose el resto del edificio que quedaba dentro de la calle.

Es de destacar cómo, y a pesar de su desaparición parcial, dejó una huella en el callejero urbano de importancia. La prolongación de la calle Villa Vieja extramuros recibió el nombre de calle Mayor, mientras que a intramuros, conservó el nombre de Villa Vieja. Este eje longitudinal estaba separado por nuestra puerta. Al ser derribada, desapareció el elemento que dividía las dos calles, pero sus nombres permanecieron, de tal manera que el último edificio de la calle Mayor es mediero con el primero de la calle Villa Vieja. Este dato, en apariencia insignificante es uno de los que nos permitieron ubicar exactamente donde estaba la Puerta Ferrissa.

La combinación de las noticias históricas, los datos de los parcelarios y callejero y la cartografía histórica, nos ha permitido el estudio de un importante elemento de la estructura urbana musulmana, además de posibilitarnos el descubrimiento de los restos arquitectónicos de la Puerta Ferrissa, que se pensaba desaparecida en su totalidad.

Esperamos que los organismos competentes tomen las medidas oportunas para su salvaguarda y llevar adelante los necesarios estudios arqueológicos que profundicen en el conocimiento de esta edificación de época musulmana, reestructura en la primera mitad del siglo XVI. 


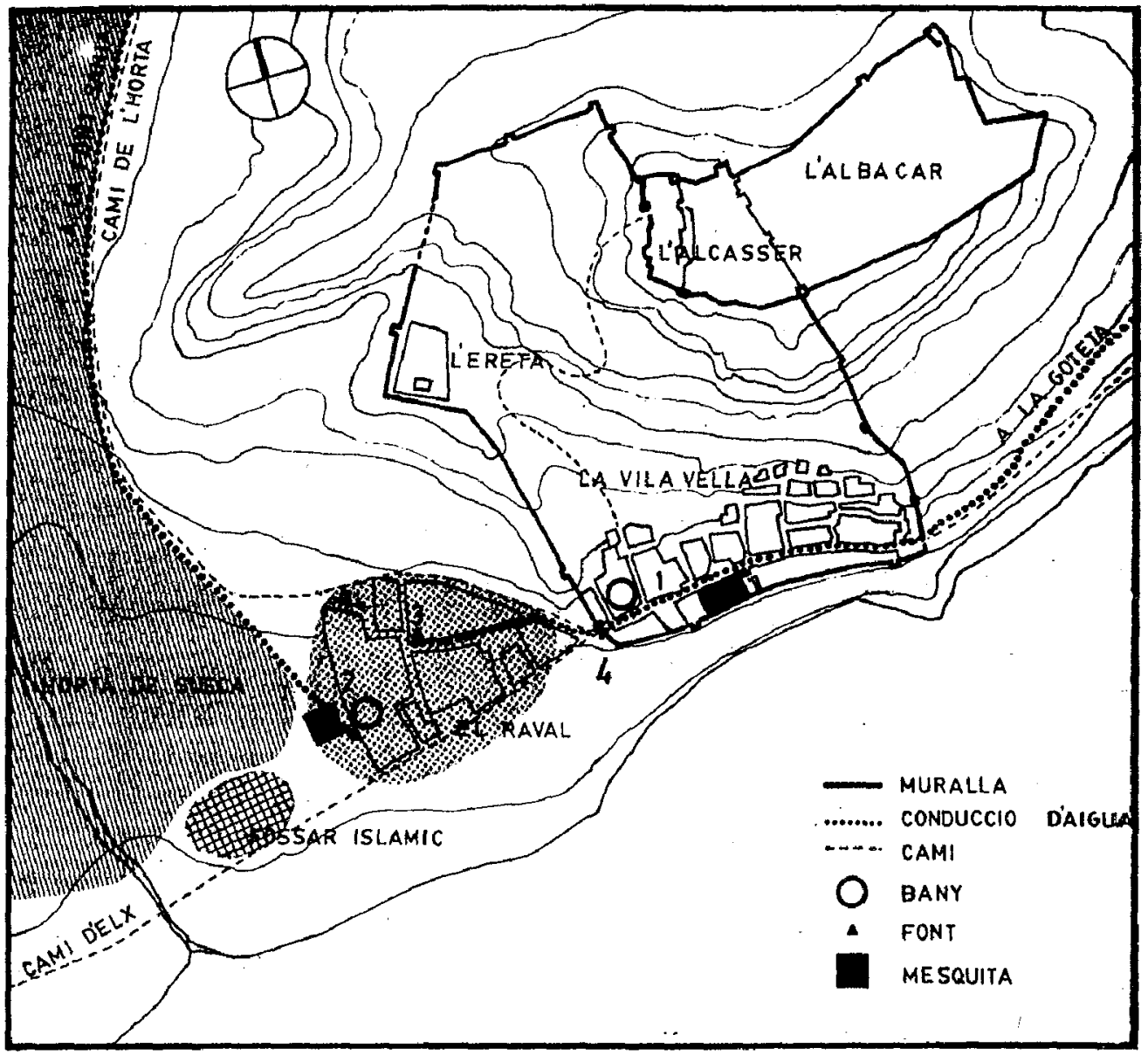

1.- La medina Laquant y su arrabal. 1) Area de ubicación de la mezquita mayor y baño en la Vila Vella. 2) Area de ubicación de la mezquita y baño del Raval. 3) Font Vella. 4) Porta Ferrissa. 


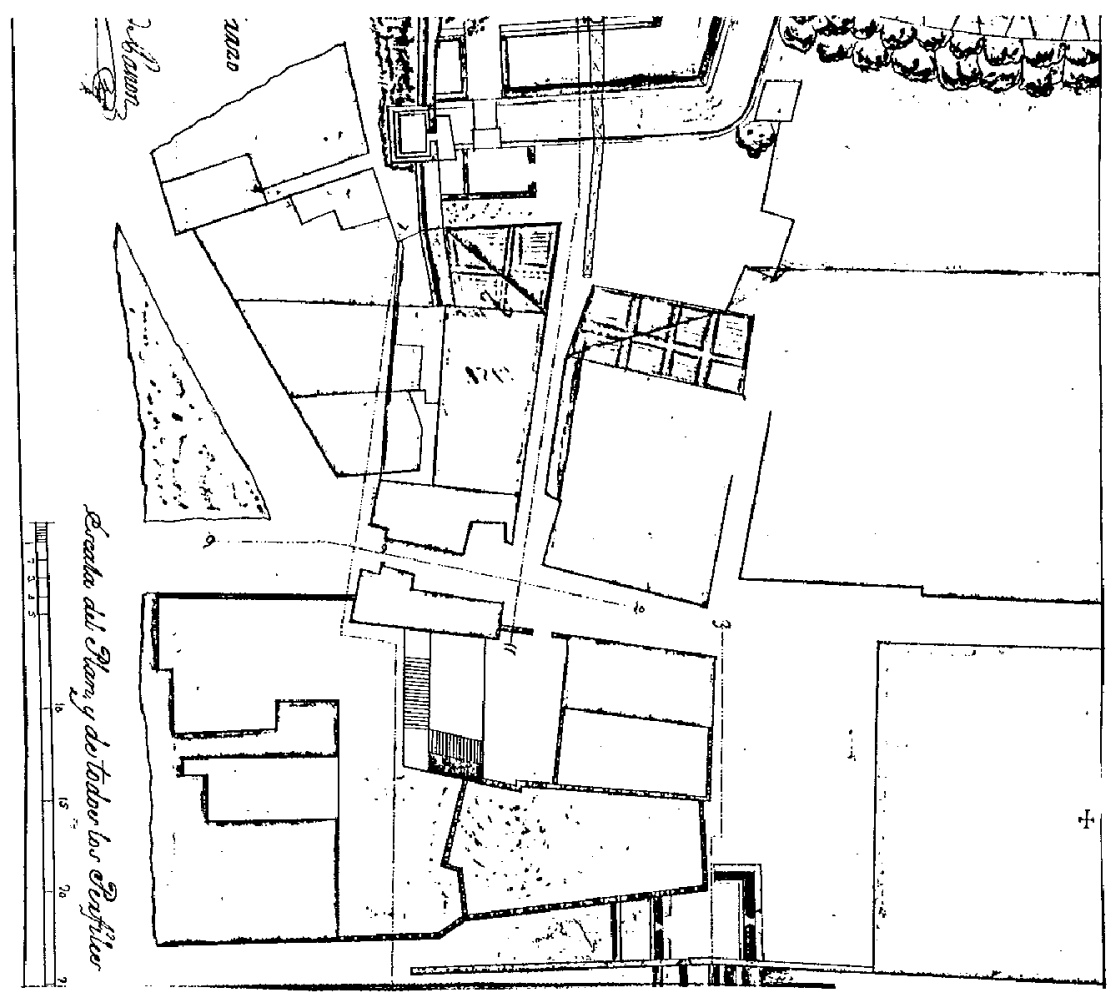

A 


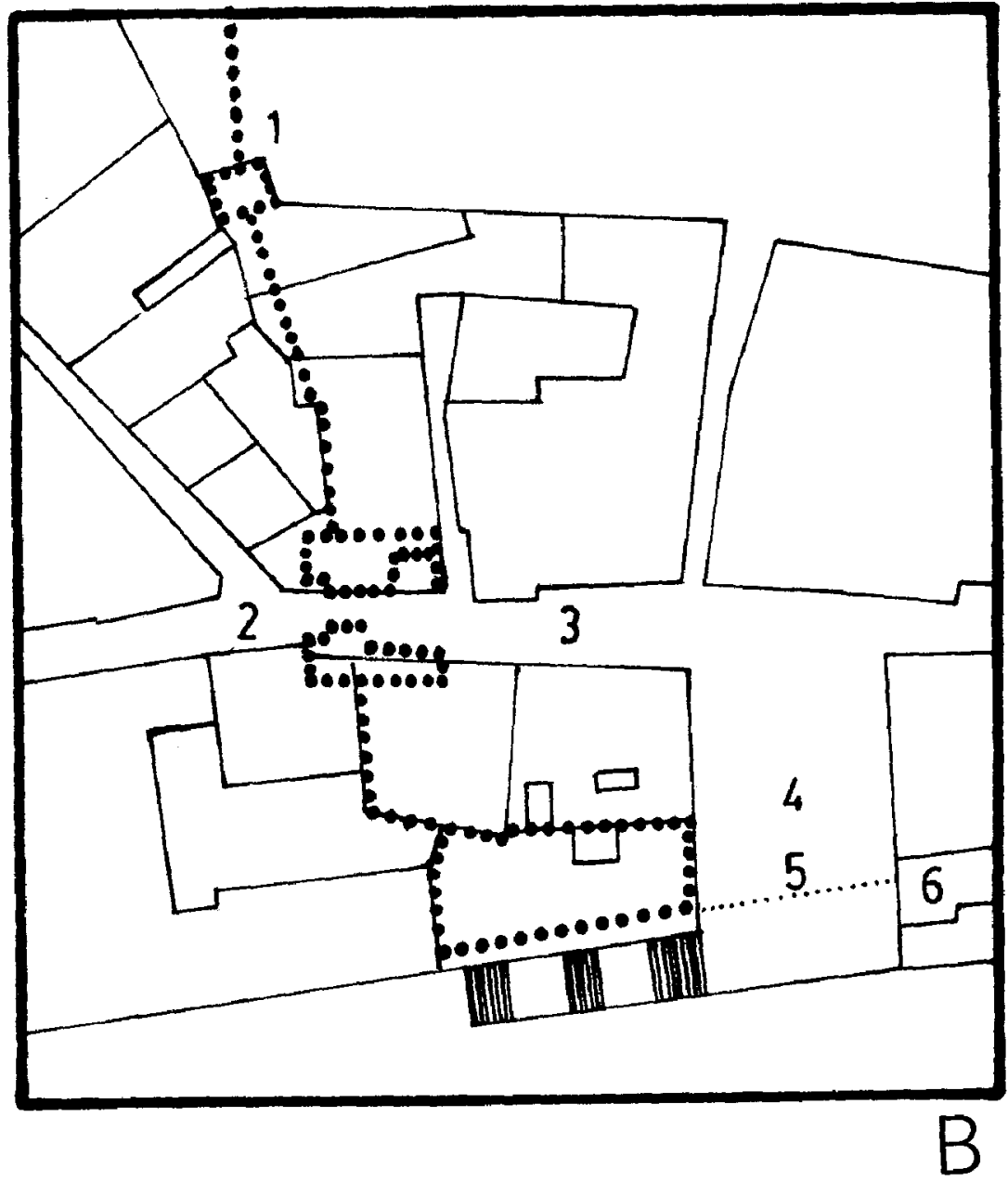

2.- A) Planta de la Porta Ferrissa, según plano de Estevan Pavón de 1551, con el parcelario de las viviendas que la rodeaban. B) Parcelario actual con el trazado de la muralla islámica y su puerta. Véase cómo su trazado coincide con las medianeras y los patios de las viviendas hoy existentes, por lo que suponemos que la muralla se conserva en buena medida en ellas. 1) Torre de la Pólvora. 2) Calle Mayor. 3) Calle Villa Vieja. 4) Plaza de Santa María. 5) Posible trazado de la muralla hasta llegar a la torre-campanario medieval de Santa María. 6) Campanario de Santa María. 


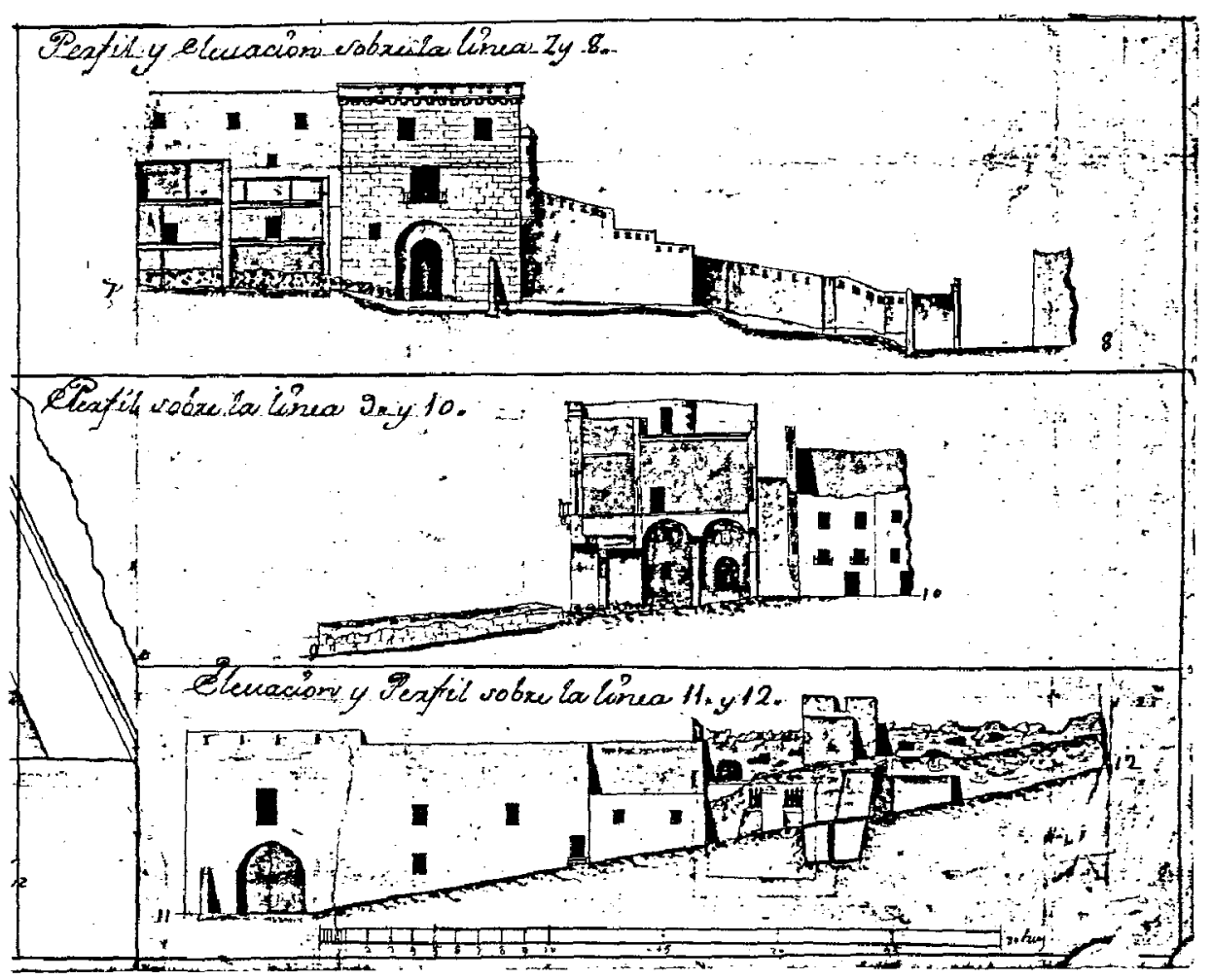

3- Alzado principal, sección y alzado posterior de la Porta Ferrissa, según el plano de Estevan Pavón 


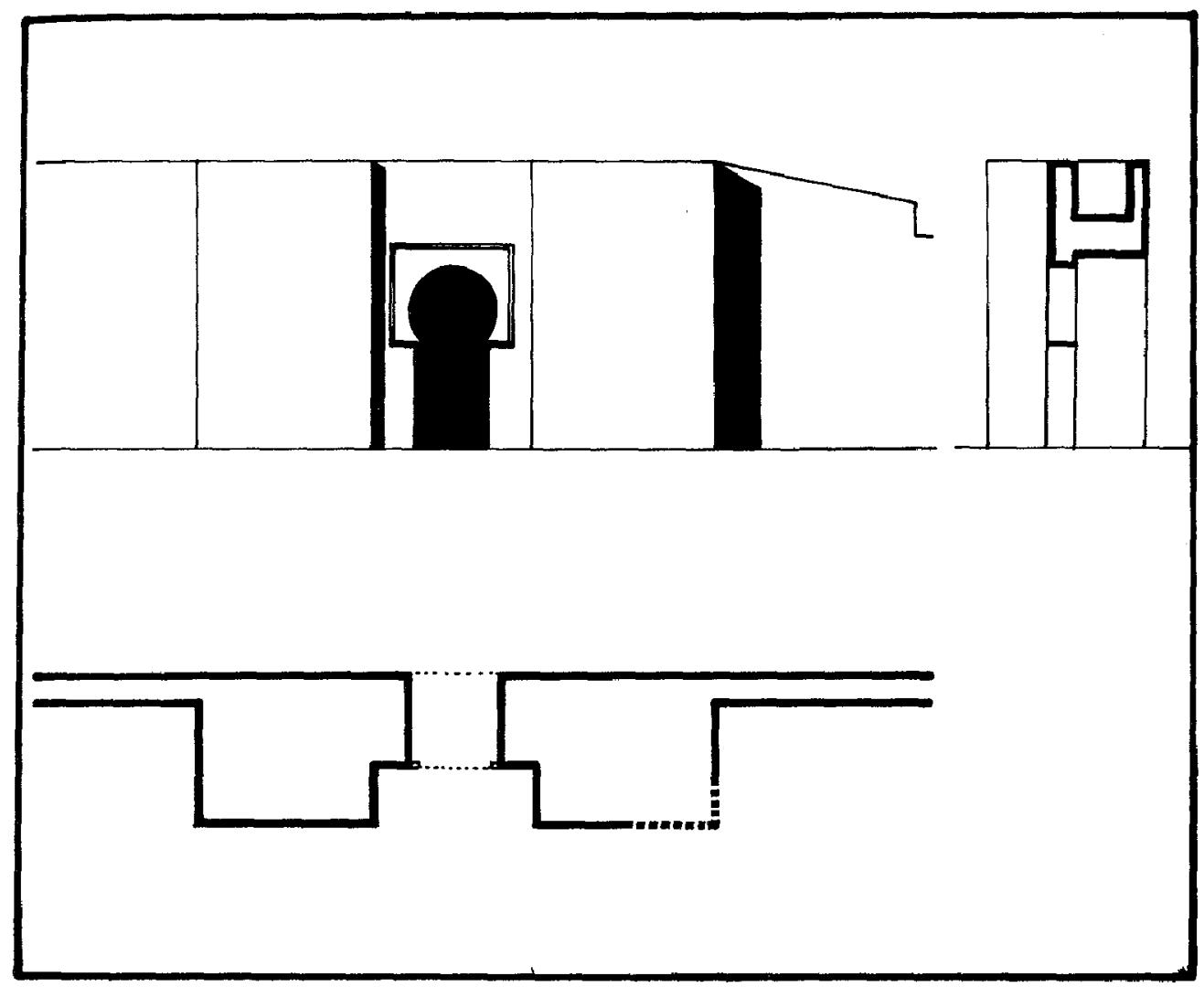

4.- Reconstrucción hipotética de la Porta Ferrissa, sin las modificaciones cristianas de los siglos XV-XVI. En trazo punteado grueso la esquina que todavía hoy se conserva. 


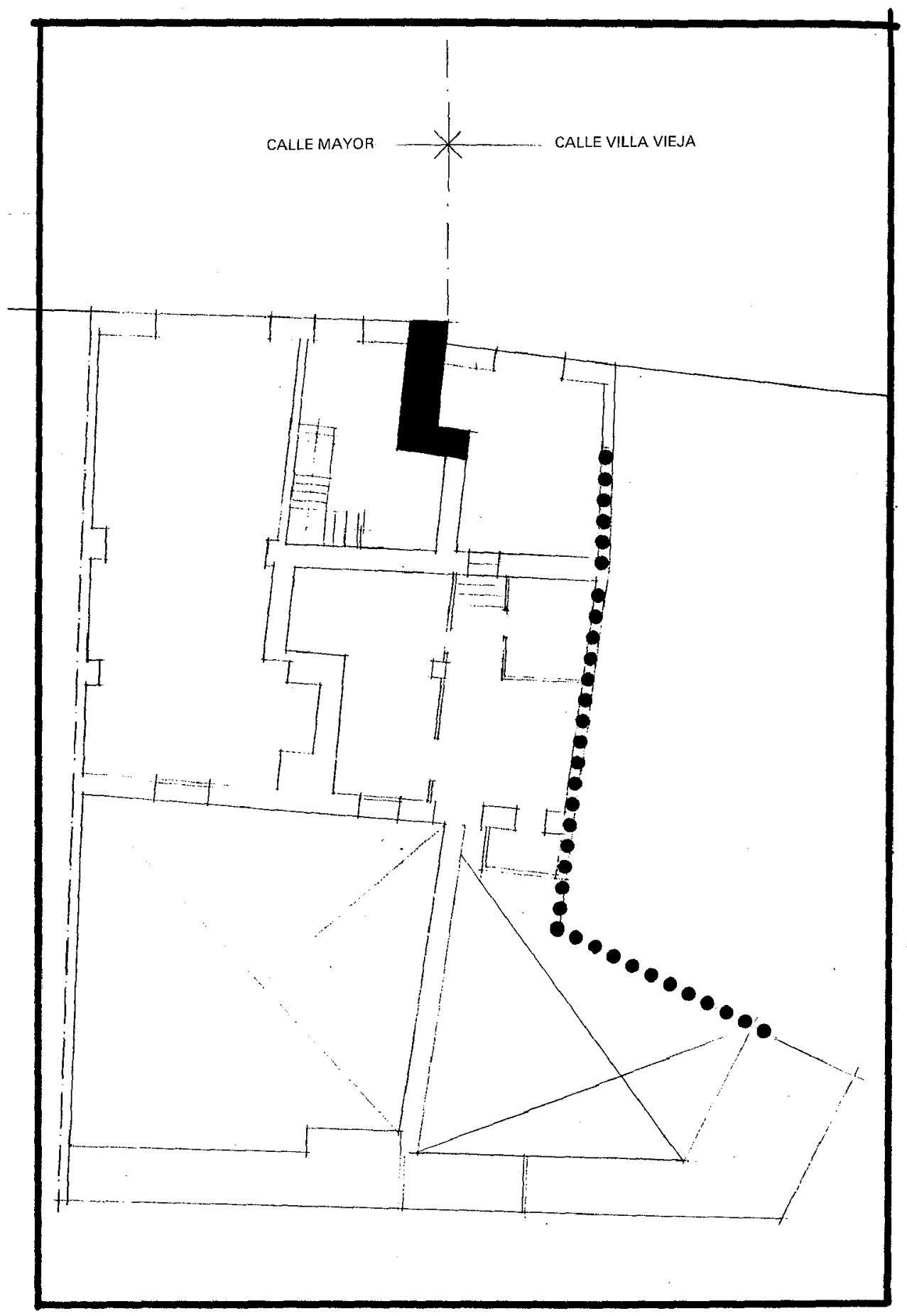

5.- Planta del edificio de la calle Mayor, n. ${ }^{\circ} 42$. En trazo grueso el resto de la puerta conservado, en trazo discontinuo posibles restos de la muralla conservada en las medianeras. 

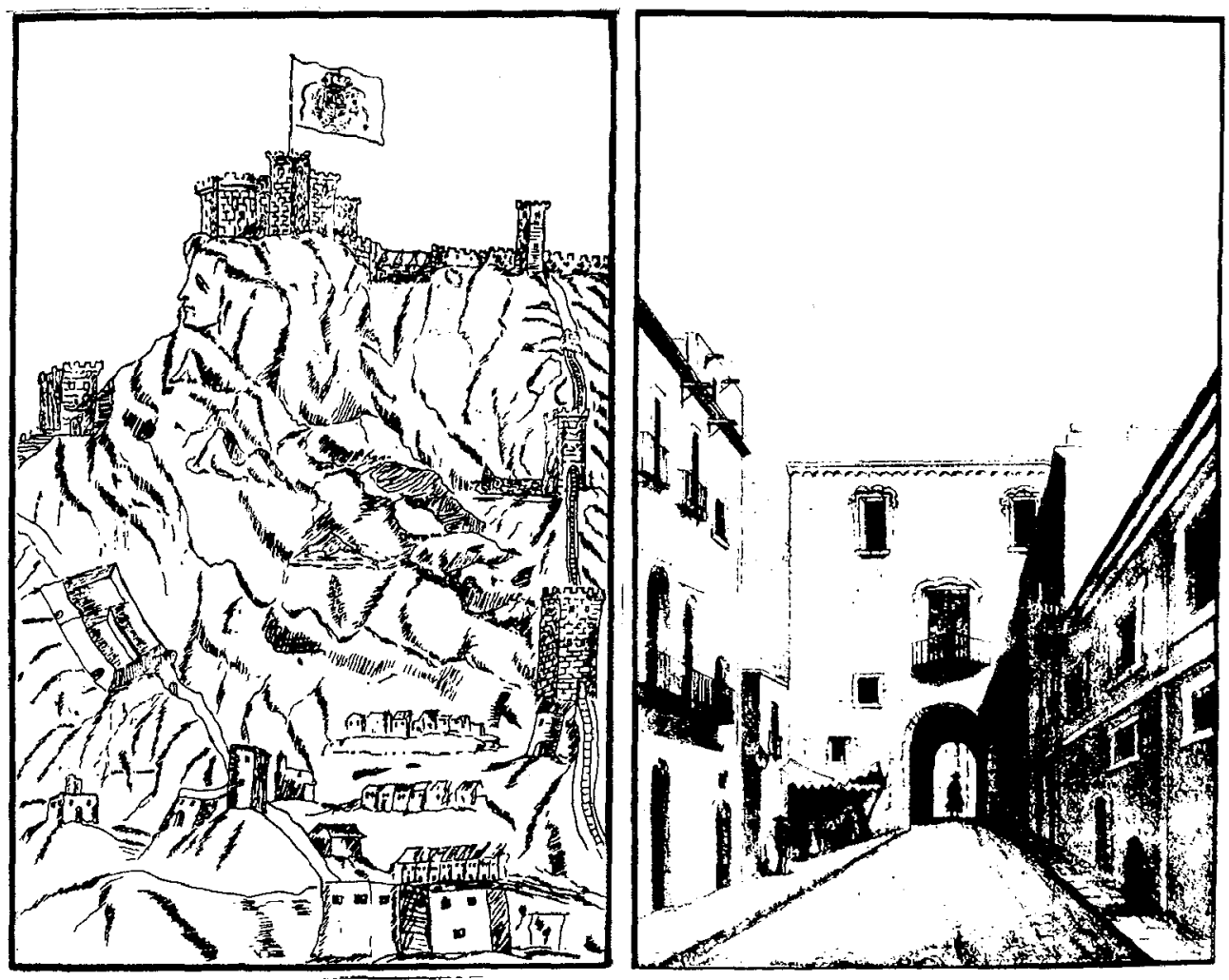

6.- Vista del Castillo de Alicante y muralla que cerraba la Vila Vella, según el cronista Bendicho. Véase en ella la edificación existente en la Ereta, la torre de la Pólvora y la Porta Ferrissa en la parte inferior.

Grabado de la Porta Ferrissa reproducido en la Crónica de Viravens, que a la vez tomó de N.C. Jover. Véase cómo la esquina derecha se mete en los edificios, hecho que ha posibilitado su conservación parcial. 